CLINICAL STUDY

\title{
Associations between cardiovascular risk, insulin resistance, $\beta$-cell function and thyroid dysfunction: a cross-sectional study in She ethnic minority group of Fujian Province in China
}

\author{
Gang Chen*, Juan $\mathrm{Wu}^{*}$, Yinghua Lin ${ }^{1, *}$, Baoying Huang ${ }^{1}$, Jin Yao, Qiqin Jiang, Junping Wen and Lixiang Lin \\ Department of Endocrinology, Fujian Provincial Hospital, Fujian Medical University, PO Box 4-704, 92 Huqian Road, Fuzhou 350001, Fujian, People's \\ Republic of China and ${ }^{1}$ Department of Endocrinology, Ningde Municipal Hospital, Ningde 352100, People's Republic of China \\ (Correspondence should be addressed to G Chen; Email: chengang18@yahoo.com; J Yao; Email: yaojin@sina.com)
}

*(G Chen, J Wu and Y Lin contributed equally to this work)

\begin{abstract}
Objective: To investigate the associations between cardiovascular risk, insulin resistance (IR), $\beta$-cell function and thyroid dysfunction in She ethnic minority group in China.

Methods: We enrolled 5080 participants of She ethnicity in this analysis eventually. We measured serum TSH and thyroid peroxidase antibody (TPOAb) concentrations, blood glucose and insulin levels in both fasting and 2-h postprandial states, serum lipid levels, blood pressure (BP), brachial-ankle pulse wave velocity (baPWV), electrophysiological parameters, including $T_{\text {peak }}-T_{\text {end }}$ interval ( $T_{\text {p-e }}$ ), QT interval and height of the R wave in lead aVL (RaVL), and anthropometric parameters.

Results: The total prevalence of thyroid dysfunction in this population is $12.1 \%$. Hyperthyroid subjects had shorter $T_{\mathrm{p}-\mathrm{e}}$ interval and QT interval in electrocardiogram (ECG), while hypothyroid subjects had shorter $T_{\mathrm{p}-\mathrm{e}}$ interval and longer QT interval in ECG than euthyroid subjects. Neither hyperthyroid nor hypothyroid subjects showed significant difference in BP, pulse pressure, and baPWV compared with euthyroid subjects. RaVL was slightly higher in hyperthyroid subjects, though the difference did not reach statistical significance $(P=0.08)$. Subjects with $\mathrm{TSH}<0.3 \mathrm{mIU} / \mathrm{l}$ had higher blood glucose, insulin, homeostasis model assessment of insulin resistance (HOMA-IR), and $\beta$-cell function (HOMA- $\beta$ ), whereas subjects with TSH $>10 \mathrm{mIU} / \mathrm{l}$ had lower insulin, HOMA-IR, and HOMA- $\beta$ than the reference group. There was a significant negative correlation, albeit weak, between TSH and HOMA-IR, HOMA- $\beta$ after adjustment for confounding factors.

Conclusions: Hypothyroid subjects may carry higher cardiovascular risk than euthyroid subjects. Moreover, IR and $\beta$-cell function are inversely correlated with TSH, which may be explained by the decreasing insulin-antagonistic effects of thyroid hormones along with increasing TSH.
\end{abstract}

European Journal of Endocrinology 163 775-782

\section{Introduction}

Thyroid dysfunction is common (1-4). Differences in prevalence rates may be due to variations in diagnostic criteria, diverse populations studied, iodine intake in different regions, and the discrepancy in the sensitivity of thyroid function measurements. The reference range for TSH according to the current recommendations from the AACE guidelines is $0.3-3.0 \mathrm{mIU} / \mathrm{l}$ (5). However, many laboratories are still using the old range, and epidemiological surveys based on a TSH reference range of $0.3-3.0 \mathrm{mIU} / \mathrm{l}$ are relatively rare. In this study, we report the prevalence of abnormal TSH according to the recent recommendations $(0.3-3.0 \mathrm{mIU} / \mathrm{l})$ and the prevalence of positive TPOAbs in the She ethnic minority group of Fujian province in China.

Thyroid dysfunction has important health implications, including increased risk of dyslipidemia, abnormal glucose intolerance, cardiovascular disorders, and so on. As is well known, dyslipidemia in thyroid disease is common (6), and thyroid dysfunction is associated with an increased cardiovascular risk (7). The mechanism by which thyroid hormones contribute to the regulation of glucose and insulin homeostasis is a complex subject. So, despite several investigations, many aspects of insulin activity dependent on thyroid status are still not quite clear. That is, the association between thyroid function and insulin resistance (IR), $\beta$-cell function is not very clear.

We undertook this study to determine the prevalence of thyroid dysfunction and thyroid peroxidase antibodies (TPOAbs) in the She ethnic minority group of Fujian province in China and to investigate the associations with other diseases and metabolic abnormalities such as lipid metabolism, cardiovascular disorders, IR, and $\beta$-cell function. 


\section{Participants and methods}

\section{Study population}

Ningde City is a middle-sized city in the northeast of Fujian province in China, with She population of 170000 , accounting for $25 \%$ of She population in China. Between April 2009 and September 2009, 5523 participants of She ethnicity aged 20-80 years, living in Ningde City, and age- and sex-stratified were randomly selected. Participants were required to complete a questionnaire, and blood samples were collected. Subjects who did not complete the questionnaire and those in whom thyroid function tests were not carried out were excluded from analyses of the other laboratory parameters. Finally, 5080 participants were enrolled in our study. All the participants signed informed consent authorized by the Diabetes Branch of the Chinese Medical Association, and the study has been approved by an ethical committee.

\section{Data collection}

After an 8- to 12-h overnight fast, blood samples were collected followed by a $75 \mathrm{~g}$ oral glucose tolerance test (OGTT), with additional blood samples being drawn at $2 \mathrm{~h}$ for the measurement of glucose and insulin. Blood samples were stored at $-20{ }^{\circ} \mathrm{C}$ until analysis. Serum TSH was assessed using a chemiluminescence immunometric assay (Nichols Institute Diagnostics, San Juan Capistrano, CA, USA). The working range for this method is $0.01-100 \mathrm{mIU} / \mathrm{l}$. The reference range for TSH was $0.3-3.0 \mathrm{mIU} / \mathrm{l}$ according to the AACE guidelines (5). Serum TPOAb levels were measured by a highly sensitive, direct RIA system (Kronus, San Clemente, CA, USA). The normal range for TPOAb in humans is $\leq 35 \mathrm{IU} / \mathrm{ml}$. Specific insulin was measured using the Elecsys 1010 immunoassay analyzer (Roche Diagnostics) and electrochemiluminescence immunoassay. Blood glucose levels were determined by the glucose oxidase method (Sclavo, Siena, Italy). Glucose tolerance status was categorized using 1999 World Health Organization criteria (8). Serum lipids (triglycerides (TG), total cholesterol (TC), and high-density lipoprotein cholesterol) were determined by an automatic colorimetric method (Hitachi; Boehringer Mannheim). Low-density lipoprotein cholesterol (LDL-C) was calculated by Friedewald formula (9).

More sophisticated indices of glucose and insulin control included the calculation of the homeostasis model (HOMA) of IR index, the HOMA $\beta$-cell index as a measure of reserve pancreatic insulin production, and the Gutt insulin sensitivity index, which includes body weight measurement and OGTT that gives glucose and insulin information and is similar to a glucose disposition index $(10,11)$.

Height and weight were recorded, and body mass index (BMI) was calculated as weight $/(\text { height })^{2}$ and expressed in $\mathrm{kg} / \mathrm{m}^{2}$. Waist circumference (WC) was taken at the level of the umbilicus with the patient in the standing position. Brachial-ankle pulse wave velocity (baPWV) was measured using an automatic device (VP-2000, Colin Co., Komaki, Japan). baPWV, blood pressure (BP), and heart rate were recorded simultaneously. We used the mean value of bilateral baPWV in our analyses. Standard 12-lead electrocardiogram was recorded with a standard digital recorder. Electrophysiological parameters, including height of the $R$ wave in lead aVL (RaVL), QT interval and $T_{\mathrm{p}-\mathrm{e}}$ interval, were manually measured.

\section{Statistical analyses}

Data analyses were conducted with SPSS 13 statistical software package (SPSS, Chicago, IL, USA). Data are presented as proportions, mean \pm s.D., or median (interquartile range) where appropriate. Statistical comparisons were performed by means of $t$-tests for data with a normal distribution, Mann-Whitney $U$ tests for data with a skewed distribution, and $\chi^{2}$ tests for percentages.

To study the influence of thyroid function on glucose control and insulin action, nondiabetic participants were divided into six groups, i.e. TSH $<0.3,0.3-0.99$, $1.0-1.99,2.0-2.99,3.0-10$, and $>10 \mathrm{mIU} / \mathrm{l}$. By using covariance analysis, blood glucose, insulin, HOMA-IR, and HOMA- $\beta$ were measured after adjusting for age, sex, serum lipids, BMI, and smoking status. Multivariate linear regression models were performed for associations of thyroid function with IR and with $\beta$-cell function. $P<0.05$ was considered statistically significant.

\section{Results}

\section{TSH and TPOAbs}

The distribution of subjects with thyroid dysfunction by age and sex is shown in Table 1. Based on an abnormal TSH alone, the prevalence of thyroid dysfunction was $12.1 \%$. Among the subjects with hypothyroidism, $8.7 \%$ had a level between 3 and $10 \mathrm{mIU} / \mathrm{l} ; 1 \%$ had a value $>10 \mathrm{mIU} / \mathrm{l}$. Females had higher prevalence of hypothyroidism than males for all age groups, but the difference was not significant in the subjects with hypothyroidism aged 20-29 years or 70-80 years.

The prevalence of positive TPOAbs was $10.8 \%$ (7.4\% of males and $13.5 \%$ of females). In all the age groups, TPOAbs were found more frequent in females than in males. The prevalence of positive TPOAbs did not change significantly with age in these subjects $(P>0.05)$.

\section{Electrophysiological, biochemical, and metabolic characteristics}

The levels of TG, TC, and LDL-C were lower, and the heart rate was significantly higher in hyperthyroid subjects than in euthyroid subjects as shown in Table 2. 
Table 1 Prevalence of thyroid abnormalities in the study.

\begin{tabular}{|c|c|c|c|c|c|}
\hline & Subjects & $\begin{array}{c}\text { Abnormal TSH } \\
n(\%)\end{array}$ & $\begin{array}{c}\text { Hyperthyroidism } \\
n(\%)\end{array}$ & $\begin{array}{c}\text { Hypothyroidism } \\
n(\%)\end{array}$ & $\begin{array}{c}\text { Positive TPOAb } \\
n(\%)\end{array}$ \\
\hline \multicolumn{6}{|l|}{ Females } \\
\hline $20-29$ & 218 & 42 (19.3\%) & $4(1.8 \%)$ & 38 (17.4\%) & 27 (12.4\%) \\
\hline $20-29$ & 652 & 92 (14.1\%) & $17(2.6 \%)$ & 75 (11.5\%) & 83 (12.8\%) \\
\hline $40-49$ & 883 & 108 (12.2\%) & 24 (2.7\%) & $84(9.5 \%)$ & $128(14.5 \%)$ \\
\hline $50-59$ & 770 & 109 (14.2\%) & 26 (3.4\%) & $83(10.8 \%)$ & 99 (12.9\%) \\
\hline $60-69$ & 294 & $45(15.3 \%)$ & $6(2.0 \%)$ & $39(13.3 \%)$ & $39(13.3 \%)$ \\
\hline $70-80$ & 76 & $13(17.1 \%)$ & $2(2.6 \%)$ & $11(14.5 \%)$ & $13(17.1 \%)$ \\
\hline \multirow{2}{*}{\multicolumn{6}{|c|}{ Males }} \\
\hline & & & & & \\
\hline $20-29$ & 218 & $23(10.6 \%)$ & $0(0 \%)$ & $23(10.6 \%)$ & $11(5.1 \%)$ \\
\hline $30-39$ & 417 & $41(9.8 \%)$ & $12(2.9 \%)$ & $29(7.0 \%)$ & $23(5.6 \%)$ \\
\hline $40-49$ & 542 & 38 (7.0\%) & $2(0.4 \%)$ & 36 (6.6\%) & $31(5.7 \%)$ \\
\hline $50-59$ & 568 & $46(8.1 \%)$ & $18(3.2 \%)$ & $28(4.9 \%)$ & $47(8.3 \%)$ \\
\hline $60-69$ & 321 & 42 (13.1\%) & 12 (3.7\%) & $30(9.3 \%)$ & 41 (12.9\%) \\
\hline $70-80$ & 121 & $16(13.2 \%)$ & $1(0.8 \%)$ & $15(12.4 \%)$ & $7(5.8 \%)$ \\
\hline All males & 2187 & $206(9.5 \%)$ & $45(2.1 \%)$ & $161(7.4 \%)$ & 160 (7.4\%) \\
\hline All subjects & 5080 & $615(12.1 \%)$ & $124(2.4 \%)$ & $491(9.7 \%)$ & $549(10.8 \%)$ \\
\hline
\end{tabular}

Hypothyroid subjects had higher BMI, TG than euthyroid subjects. Neither hyperthyroid nor hypothyroid subjects showed significant difference in BP, pulse pressure (PP), and baPWV compared with euthyroid subjects. The prevalence of hypertension in different thyroid status was similar with no statistical significance. For electrophysiological parameters, we found that QT interval and $T_{\mathrm{p}-\mathrm{e}}$ interval shortened significantly in hyperthyroid subjects, but $T_{\mathrm{p}-\mathrm{e}} / \mathrm{QT}$ ratio did not show significant differences in the euthyroid group. On the other hand, the hypothyroid group had a longer
QT interval, a shorter $T_{\mathrm{p}-\mathrm{e}}$ interval, and a smaller $T_{\mathrm{p}-\mathrm{e}} / \mathrm{QT}$ ratio than euthyroid group. In addition, RaVL did not show obvious and significant differences between hyperthyroid and euthyroid subjects. However, RaVL was slightly higher in hyperthyroid subjects, though the difference did not reach statistical significance $(P=0.08)$.

With regard to glucose metabolism, we found that the prevalence of abnormal glucose tolerance (impaired glucose tolerance (IGT) and diabetes mellitus (DM)) in hyperthyroidism was $55.7 \% \quad(45.2$ and $10.5 \%$

Table 2 Characteristics of the subjects categorized by thyroid status. Data are expressed as mean \pm s.D. or \%.

\begin{tabular}{|c|c|c|c|}
\hline & $\begin{array}{l}\text { Euthyroidism } \\
\quad(n=4465)\end{array}$ & $\begin{array}{l}\text { Hyperthyroidism } \\
\quad(n=124)\end{array}$ & $\begin{array}{l}\text { Hypothyroidism } \\
\quad(n=491)\end{array}$ \\
\hline Age (years) & $46.87 \pm 12.28$ & $48.44 \pm 11.47$ & $46.457 \pm 13.89$ \\
\hline $\mathrm{BMI}\left(\mathrm{kg} / \mathrm{m}^{2}\right)$ & $22.76 \pm 3.07$ & $22.42 \pm 3.24$ & $23.26 \pm 3.53^{\dagger}$ \\
\hline WC (cm) & $78.04 \pm 8.84$ & $78.01 \pm 8.78$ & $78.52 \pm 8.93$ \\
\hline $\mathrm{SBP}(\mathrm{mmHg})$ & $134.2 \pm 23.04$ & $137.18 \pm 24.86$ & $135.52 \pm 26.25$ \\
\hline $\mathrm{DBP}(\mathrm{mmHg})$ & $79.86 \pm 13.28$ & $80.63 \pm 13.75$ & $80.18 \pm 13.66$ \\
\hline $\mathrm{PP}(\mathrm{mmHg})$ & $54.33 \pm 13.95$ & $56.54 \pm 14.44$ & $55.34 \pm 17.07$ \\
\hline baPWV (cm/s) & $1447 \pm 388$ & $1490 \pm 383$ & $1472 \pm 386$ \\
\hline HR (bpm) & $74.36 \pm 14.27$ & $86 \pm 19.59^{\ddagger}$ & $73.5 \pm 13.07$ \\
\hline$T_{\mathrm{p}-\mathrm{e}}(\mathrm{ms})$ & $0.116 \pm 0.024$ & $0.110 \pm 0.024^{\dagger}$ & $0.113 \pm 0.025^{\star}$ \\
\hline QT interval (ms) & $0.401 \pm 0.041$ & $0.377 \pm 0.047^{\ddagger}$ & $0.406 \pm 0.042^{\dagger}$ \\
\hline$T_{\mathrm{p}-\mathrm{e}} / \mathrm{QT}$ ratio & $0.289 \pm 0.055$ & $0.291 \pm 0.057$ & $0.279 \pm 0.058^{\ddagger}$ \\
\hline $\operatorname{RaVL}(\mathrm{mV})$ & $0.263 \pm 0.243$ & $0.269 \pm 0.270$ & $0.280 \pm 0.249$ \\
\hline TG $(\mathrm{mmol} / \mathrm{l})$ & $1.07(0 . \overline{7} 7-1.57)$ & $0.98(0 . \overline{7}-1.41)^{\star}$ & $1.15(0 . \overline{79}-1.69)^{\star}$ \\
\hline TC (mmol/l) & $4.95 \pm 1.4$ & $4.65 \pm 1.17^{\star}$ & $4.97 \pm 1.1$ \\
\hline HDL-C (mmol/l) & $1.48 \pm 0.33$ & $1.43 \pm 0.36$ & $1.48 \pm 0.32$ \\
\hline LDL-C (mmol/l') & $3.19 \pm 0.87$ & $2.96 \pm 0.89^{*}$ & $3.2 \pm 0.91$ \\
\hline TSH (mIU/l) & $1.38(0.97-1.9)$ & $0.01(0.01-0.17)^{\ddagger}$ & $3.89(3.33-5.1)^{\ddagger}$ \\
\hline Positive TPOAbs (\%) & 8 & $56.6^{\ddagger}$ & $25.4^{\ddagger}$ \\
\hline Hypertension (\%) & 37.3 & 37.9 & 41.1 \\
\hline IGR (\%) & 32 & $45.2^{\ddagger}$ & 33 \\
\hline DM (\%) & 5.9 & $10.5^{\ddagger}$ & 4.1 \\
\hline
\end{tabular}

HR, heart rate; IGR, impaired glucose regulation. ${ }^{*}$ Compared with euthyroidism, $P<0.05 ;{ }^{\dagger}$ Compared with euthyroidism, $P<0.01 ;{ }^{\ddagger}$ Compared with euthyroidism, $P<0.001$. TG and TSH are shown as median and interquartile range. 


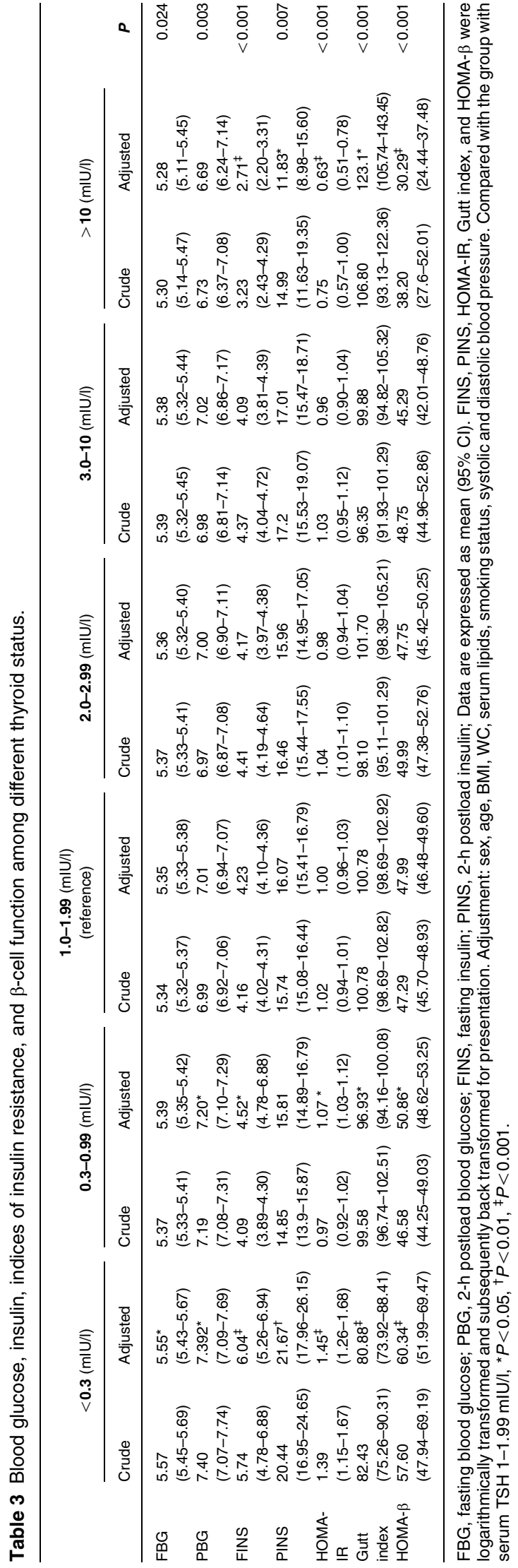

respectively), much higher than in euthyroidism, but there was no significant difference between hypothyroidism and euthyroidism. To avoid confusion, diabetic patients and those subjects on therapy that could interfere with glucose and lipid metabolism were excluded when we investigated the relationship between IR, $\beta$-cell function and thyroid function. To study the glucose metabolism morespecifically, we divided the nondiabetic participants into six groups according to the levels of serum TSH, i.e. TSH $<0.3,0.3-0.99$, $1.0-1.99,2.0-2.99,3.0-10$, and $>10 \mathrm{mIU} / \mathrm{l}$ (Table 3). Group with a TSH between 1.0 and $1.99 \mathrm{mIU} / \mathrm{l}$ had the largest number of subjects $(n=2329)$. By using covariance analysis, blood glucose, insulin, HOMA-IR, Gutt index, and HOMA- $\beta$ were measured after adjusting for age, sex, blood lipids, BMI, and smoking status. The results showed that hyperthyroid subjects (TSH $<0.3 \mathrm{mIU} / \mathrm{l})$ had higher levels of blood glucose, insulin, HOMA-IR, HOMA- $\beta$, and lower Gutt index than any other group, whereas subjects with TSH $>10 \mathrm{mIU} / \mathrm{l}$ had lower levels of insulin, HOMA-IR, HOMA- $\beta$, and higher Gutt index than any other group. All variables regarding glucose metabolism in subjects with moderately elevated TSH $(3.0-10 \mathrm{mIU} / \mathrm{l})$ did not show significant differences from the group with serum TSH of $1.0-1.99 \mathrm{mIU} / \mathrm{l}$.

A multivariate linear regression analysis for the associations between TSH and IR, $\beta$-cell function is shown in Table 4 . There was a significant negative correlation between TSH and HOMA-IR, HOMA- $\beta$ after adjustment for sex, age, BMI, serum lipids, smoking status, and systolic (SBP) and diastolic BP (DBP).

\section{Discussion}

In this study, the total prevalence of thyroid dysfunction based on an abnormal TSH alone was $12.1 \%$ (14.1\% in women and $9.5 \%$ in men), and the prevalence of positive TPOAbs was $10.8 \%(7.4 \%$ of males and $13.5 \%$ of females). As expected, the prevalence of hypothyroidism and positive TPOAbs in females was higher than that in males. The prevalence of hypothyroidism increased with age among the females (but not in males) aged $>40$ years, which was similar to other studies (1-3). Increasing serum thyroid antibody prevalence with age had been reported in other studies $(1,4)$, but in this study, the prevalence of positive TPOAbs did not change significantly with age $(P>0.05)$.

In this study, the levels of TG, TC, and LDL-C in hyperthyroid subjects were decreased, while the TG level was higher in hypothyroid subjects than in euthyroid subjects. These changes in the lipid profile are explained by the regulatory effect of thyroid hormones on the activity of some key enzymes of lipoprotein metabolism (12). Hypothyroid subjects had higher BMI than euthyroid subjects, which was consistent with the results of many other studies (13). 
Table 4 Full multiple linear regression models examining associations of TSH with indices of insulin resistance and $\beta$-cell function in nondiabetics.

\begin{tabular}{|c|c|c|c|c|c|c|}
\hline \multirow{3}{*}{$\begin{array}{l}\text { Independent } \\
\text { variable }\end{array}$} & \multicolumn{6}{|c|}{ Dependent variable } \\
\hline & \multicolumn{3}{|c|}{ Log HOMA-IR } & \multicolumn{3}{|c|}{ Log HOMA- $\beta$} \\
\hline & $\beta$ & $t$ & $P$ value & $\beta$ & $t$ & $P$ value \\
\hline Log TSH & -0.096 & -6.244 & -0.001 & -0.073 & -4.67 & $<0.001$ \\
\hline
\end{tabular}

Linear regression models adjusted for age, sex, BMI, WC, TC, TG, HDL-C LDL-C, smoking status, and systolic and diastolic blood pressure.

In this study, we demonstrated that neither hyperthyroid nor hypothyroid subjects showed significant difference in BP, PP, and baPWV compared with euthyroid subjects. PP and baPWV, which reflect arterial stiffening, have prognostic value for cardiovascular disease. It has been reported that thyroid dysfunction, even in the subclinical stage, was associated with increased arterial stiffness (14-16). However, we found that vascular function assessed by baPWV and PP did not change in hyperthyroidism or hypothyroidism in this study, which probably is because the course of thyroid disorder was not long enough to impair the vascular function or probably due to the limit of sample size.

An increasing number of studies have suggested that the $T_{\mathrm{p}-\mathrm{e}}$ interval may correspond to the transmural dispersion of repolarization, and that prolonged $T_{\mathrm{p}-\mathrm{e}}$ interval and greater $T_{\mathrm{p}-\mathrm{e}} / \mathrm{QT}$ ratio are associated with malignant ventricular arrhythmias (17). In this study, we used the $T_{\mathrm{p}-\mathrm{e}}$ interval and the $T_{\mathrm{p}-\mathrm{e}} / \mathrm{QT}$ ratio as electrocardiographic indices of ventricular arrhythmias. The most likely explanation for shortened $T_{\mathrm{p}-\mathrm{e}}$ interval and QT interval in hyperthyroid subjects may be due to accelerated heart rate, and because both QT interval and $T_{\mathrm{p}-\mathrm{e}}$ interval were shortened, the $T_{\mathrm{p}-\mathrm{e}} / \mathrm{QT}$ radio did not change significantly compared with the euthyroid group. On the other hand, interestingly, hypothyroid subjects show a shortened $T_{\mathrm{p}-\mathrm{e}}$ interval and a smaller $T_{\mathrm{p}-\mathrm{e}} / \mathrm{QT}$ ratio than the euthyroid group. As mentioned above, prolonged $T_{\mathrm{p}-\mathrm{e}}$ interval and greater $T_{\mathrm{p}-\mathrm{e}} / \mathrm{QT}$ ratio are associated with ventricular arrhythmias, but whether shortened $T_{\mathrm{p}-\mathrm{e}}$ interval and smaller $T_{\mathrm{p}-\mathrm{e}} / \mathrm{QT}$ ratio are associated with ventricular arrhythmias is uncertain. This study showed a shortened $T_{\mathrm{p}-\mathrm{e}}$ interval and a smaller $T_{\mathrm{p}-\mathrm{e}} / \mathrm{QT}$ ratio in the hypothyroid group.

With regard to RaVL, a very recent prospective study (18) focused on the $\mathrm{R}$ wave voltage in lead aVL as being rather closely associated with left ventricular mass (LVM), and additionally being predictive of incident cardiovascular events in hypertensive patients. In this study, we also used this electrophysiological parameter to study the association between LVM and thyroid function. We found that neither hyperthyroid nor hypothyroid subjects showed significant difference in RaVL compared with euthyroid subjects.
However, RaVL was slightly higher in hyperthyroid subjects, though the difference did not reach statistical significance $(P=0.08)$. Many studies $(19,20)$ have found that hypothyroidism, even in the subclinical stage, was associated with ischemic heart disease (IHD). As we know, the latter can lead to left ventricular hypertrophy, which is an important prognosis factor for IHD, so hypothyroid subjects may increase the risk of cardiovascular events. The lack of statistical significance $(P=0.08)$ in RaVL of hypothyroid subjects was probably due to the limited sample size.

It is well known that hyperthyroidism is frequently associated with impaired glucose tolerance. The prevalence of abnormal glucose tolerance in subjects with hyperthyroidism $(55.7 \%)$ observed in this study was much higher than that observed in subjects with hypothyroidism or euthyroidism. In nondiabetic subjects, we found that those with serum TSH $<0.3 \mathrm{mIU} / \mathrm{l}$ showed higher levels of glucose and insulin both in the fasting state and after load, higher HOMA-IR and HOMA- $\beta$, and lower Gutt index than any other group in this study. We believe that the increase in blood glucose observed in this study might be the initial step of action of thyroid hormone excess. It is well known that thyroid hormones can increase gluconeogenesis, glycogenolysis, intestinal glucose absorption, and so on. The insulin levels were increased in this study partly because of increased glucose-stimulated insulin secretion (GSIS). Another important reason for the increase was IR. IR is common in hyperthyroidism (21, 22 ), and hepatic IR in hyperthyroidism is a rather consistent finding (21). Besides, IR in peripheral tissues (adipose tissue or skeletal muscle) is also reported in hyperthyroidism $(23,24)$. In hyperthyroidism, pancreatic $\beta$-cells secrete more insulin to compensate for the increased demand of insulin when plasma glucose increases and IR exists, which leads to an apparent increase in $\beta$-cell secretory function (a higher HOMA- $\beta$ ) in this study. However, in one study in rats, it has been reported that thyroxine $\left(\mathrm{T}_{4}\right)$ treatment increased the rate of $\beta$-cell apoptosis and then reduced insulin in pancreas and GSIS (25), and in another study, it was found that thyroid hormones reduced insulin content of $\beta$-cells, probably through inhibition of proinsulin mRNA which results in delayed inhibition of GSIS (26). However in this study, we did not find the effects of impaired $\beta$-cell function in hyperthyroidism. We think that it is in a stage of compensatory hyperfunction of $\beta$-cell. As reported in a recent follow-up study (27), HOMA $\beta$-cell function increased between years 4 and 3 before diagnosis and then decreased until diagnosis of diabetes, which suggested that it would take several years before the impairment of $\beta$-cell function. Hyperthyroid subjects usually receive treatment in time, so the course of thyroid disorder is not long enough to impair $\beta$-cell function.

On the other hand, the hypothyroid patients with moderately elevated TSH values (3.0-10 mIU/l) did not 
show differences in glucose, insulin, HOMA-IR, and HOMA- $\beta$ compared with the reference group with serum TSH values (1.0-1.99 mIU/l), while those with markedly elevated TSH values $(>10 \mathrm{mIU} / \mathrm{l})$ showed lower insulin levels both in the fasting state and after load, lower HOMA-IR and HOMA- $\beta$ than any other group. In most other studies, the concentration of insulin in hypothyroidism is reported to be normal (28) or decreased $(29,30)$, which is similar to our result. Insulin sensitivity in hypothyroid patients has been found to be normal (31) or decreased (32-34). Hypothyroidism, even in the subclinical stage, has been shown to be associated with IR $(35,36)$. Our findings were different from these studies. A significant lower HOMA-IR (associated with a lower HOMA- $\beta$ ) was observed when we analyzed the participants with markedly elevated TSH values ( $>10 \mathrm{mIU} / \mathrm{l})$, suggesting that insulin sensitivity was increased in this group. Only one study reported an increased sensitivity of glucose disposal to insulin in hypothyroidism (37), which was somewhat similar to this study.

In order to further understand the relationship between thyroid function and IR and insulin secretion of $\beta$-cells, a multivariate linear regression analysis with HOMA-IR or HOMA- $\beta$ as the outcome was used. We found a significant negative correlation, albeit weak, between TSH and IR assessed by HOMA-IR index, which was contrary to other studies (38-40). In a trial with thyroid hormones in obesity, a positive correlation between IR parameters and serum TSH was significantly influenced by the BMI (40). In fact, most of the IR parameters were related to obesity and dyslipidemia. Some studies also suggested that thyroid function might cause dyslipidemia through altered insulin sensitivity in healthy subjects (41) and patients with type 2 diabetes mellitus (42). However, we found that HOMA-IR was diminished in the group with serum TSH $>10 \mathrm{mIU} / \mathrm{l}$, even though TG, LDL levels, and BMI were significantly higher in this group (data not shown), suggesting that obesity and dyslipidemia in hypothyroidism were not associated with IR in this study. There are some other mechanisms that may be responsible for these observations. Generally, there is a negative correlation between TSH and thyroid hormones. The higher serum TSH usually means the lower thyroid hormones via negative feedback. HOMA-IR decreased as TSH increased, which may be interpreted as a negative correlation between insulin sensitivity and thyroid hormones. It is well known that thyroid hormones have insulin-antagonistic effects. As TSH increased, thyroid hormones decreased and insulinantagonistic effects weakened. It may be the main mechanism for these results. Besides, it is also possible that the course of thyroid disorder in this study was not long enough to impact the insulin sensitivity in hypothyroidism. On the other hand, the negative correlation between serum TSH and HOMA- $\beta$ in this study could be interpreted as an influence of the altered insulin sensitivity on the secretion of $\beta$-cells.

After all, further study on the magnitude of contribution of thyroid hormones, either tri-iodothyronine $\left(\mathrm{T}_{3}\right)$ or $\mathrm{T}_{4}$, to the insulin action and development of glucose intolerance is needed.

This study has several limitations. First, due to insufficient serum, $\mathrm{T}_{3}$ and $\mathrm{T}_{4}$ levels were not measured, which may have resulted in some misclassification (e.g. pituitary disease). And it was not able to subclassify accurately persons with an abnormal TSH as having subclinical versus overt disease. Secondly, this study was cross-sectional, so its ability to infer causality is limited. Thirdly, we did not detect TgAb and also TgAbs to have prevalence of thyroid antibodies only for TPOAbs. However, TPOAbs are now considered as a more important marker for autoimmune thyroid disease than TgAbs. Fourthly, because HOMA uses fasting values for estimation, it mostly describes hepatic IR and steady-state insulin secretion in this study. Moreover, we did not have access to direct measures of IR and $\beta$-cell function. Although euglycemic hyperinsulinemic clamp technique (Clamp-IR) is the standard method for the measurement of insulin sensitivity, its invasiveness and high cost have limited its use in clinical practice. The OGTT is less precise (43) but simpler to perform and is often used in large epidemiological or intervention studies.

In conclusion, this survey investigated the prevalence of thyroid disorders and its associations with cardiovascular risk, IR, and $\beta$-cell function. Vascular function did not show difference among different thyroid states. Thyroid dysfunction was associated with some ECG changes, suggesting that hypothyroid subjects may carry higher cardiovascular risk than euthyroid subjects. We also found a significant negative correlation, albeit weak, between IR, insulin secretion and TSH, which may be explained by the decreasing insulinantagonistic effects of thyroid hormones along with increasing TSH.

\section{Declaration of interest}

The authors declare that there is no conflict of interest that could be perceived as prejudicing the impartiality of the research reported.

\section{Funding}

This work was supported by grants C071002 and 2009Y0011 for natural science foundation from Fujian province of China and grant from the Ministry of Health of the People's Republic of China (WKJ 2005-2-021).

\section{References}

1 Tunbridge WM, Evered DC, Hall R, Appleton D, Brewis M, Clark F, Evans JG, Young E, Bird T \& Smith PA. The spectrum of thyroid disease in a community: the Whickham survey. Clinical Endocrinology $1977 \quad 7 \quad 481-493$. (doi:10.1111/j.1365-2265. 1977.tb01340.x) 
2 Canaris GJ, Manowitz NR, Mayor G \& Ridgway EC. The Colorado thyroid disease prevalence study. Archives of Internal Medicine 2000 160 526-534. (doi:10.1001/archinte.160.4.526)

3 O'Leary PC, Feddema PH, Michelangeli VP, Leedman PJ, Chew GT, Knuiman M, Kaye J \& Walsh JP. Investigations of thyroid hormones and antibodies based on a community health survey: the Busselton thyroid study. Clinical Endocrinology 2006 64 97-104. (doi:10.1111/j.1365-2265.2005.02424.x)

4 Hollowell JG, Staehling NW, Flanders WD, Hannon WH, Gunter EW, Spencer CA \& Braverman LE. Serum TSH, T(4), and thyroid antibodies in the United States population (1988 to 1994): National Health and Nutrition Examination Survey (NHANES III). Journal of Clinical Endocrinology and Metabolism 2002 87 489-499. (doi:10.1210/jc.87.2.489)

5 Gharib H, Tuttle RM, Baskin HJ, Fish LH, Singer PA \& McDermott MT. Subclinical thyroid dysfunction: a joint statement on management from the American Association of Clinical Endocrinologists, the American Thyroid Association, and the Endocrine Society. Endocrine Practice 200410 497-501.

6 Duntas LH. Thyroid disease and lipids. Thyroid 200212 287-293. (doi:10.1089/10507250252949405)

7 Klein I \& Danzi S. Thyroid disease and the heart. Circulation 2007 116 1725-1735. (doi:10.1161/CIRCULATIONAHA.106.678326)

8 World Health Organization. Definition, Diagnosis and Classification of Diabetes Mellitus and its Complications. Part 1: Diagnosis and Classification of Diabetes Mellitus, 1999.

9 Friedewald WT, Levy RI \& Fredrickson DS. Estimation of the concentration of low-density lipoprotein cholesterol in plasma, without use of the preparative ultracentrifuge. Clinical Chemistry 197218 499-502.

10 Matthews DR, Hosker JP, Rudenski AS, Naylor BA, Treacher DF \& Turner RC. Homeostasis model assessment: insulin resistance and $\beta$-cell function from fasting plasma glucose and insulin concentrations in man. Diabetologia 198528 412-419. (doi:10.1007/ BF00280883)

11 Gutt M, Davis CL, Spitzer SB, Llabre MM, Kumar M, Czarnecki EM, Schneiderman N, Skyler JS \& Marks JB. Validation of the insulin sensitivity index (ISI $(0,120))$ : comparison with other measures. Diabetes Research and Clinical Practice 200047 177-184. (doi:10. 1016/S0168-8227(99)00116-3)

12 Liberopoulos EN \& Elisaf MS. Dyslipidemia in patients with thyroid disorders. Hormones $20021218-223$.

13 Knudsen N, Laurberg P, Rasmussen LB, Bulow I, Perrild H, Ovesen L \& Jorgensen T. Small differences in thyroid function may be important for body mass index and the occurrence of obesity in the population. Journal of Clinical Endocrinology and Metabolism 200590 4019-4024. (doi:10.1210/jc.2004-2225)

14 Palmieri EA, Fazio S, Palmieri V, Lombardi G \& Biondi B. Myocardial contractility and total arterial stiffness in patients with overt hyperthyroidism: acute effects of $\beta 1$-adrenergic blockade. European Journal of Endocrinology 2004150 757-762. (doi:10.1530/eje.0.1500757)

15 Nagasaki T, Inaba M, Kumeda Y, Hiura Y, Shirakawa K, Yamada S, Henmi Y, Ishimura E \& Nishizawa Y. Increased pulse wave velocity in subclinical hypothyroidism. Journal of Clinical Endocrinology and Metabolism 200691 154-158. (doi:10.1210/ jc.2005-1342)

16 Owen PJ, Sabit R \& Lazarus JH. Thyroid disease and vascular function. Thyroid $2007 \mathbf{1 7}$ 519-524. (doi:10.1089/thy.2007. 0051)

17 Gupta P, Patel C, Patel H, Narayanaswamy S, Malhotra B, Green JT \& Yan GX. T(p-e)/QT ratio as an index of arrhythmogenesis. Journal of Electrocardiology $2008 \mathbf{4 1}$ 567-574. (doi:10.1016/ j.jelectrocard.2008.07.016)

18 Verdecchia P, Angeli F, Cavallini C, Mazzotta G, Repaci S, Pede S, Borgioni C, Gentile G \& Reboldi G. The voltage of R wave in lead aVL improves risk stratification in hypertensive patients without ECG left ventricular hypertrophy. Journal of Hypertension 200927 1697-1704. (doi:10.1097/HJH.0b013e32832c0031)
19 Walsh JP, Bremner AP, Bulsara MK, O'Leary P, Leedman PJ, Feddema P \& Michelangeli V. Subclinical thyroid dysfunction as a risk factor for cardiovascular disease. Archives of Internal Medicine 2005165 2467-2472. (doi:10.1001/archinte.165.21.2467)

20 Razvi S, Weaver JU, Vanderpump MP \& Pearce SH. The incidence of ischemic heart disease and mortality in people with subclinical hypothyroidism: reanalysis of the Whickham Survey Cohort. Journal of Clinical Endocrinology and Metabolism 201095 1734-1740. (doi:10.1210/jc.2009-1749)

21 Dimitriadis GD \& Raptis SA. Thyroid hormone excess and glucose intolerance. Experimental and Clinical Endocrinology and Diabetes 2001109 (Supplement 2) S225-S239. (doi:10.1055/s-200118584)

22 Shen DC \& Davidson MB. Hyperthyroid Graves' disease causes insulin antagonism. Journal of Clinical Endocrinology and Metabolism 198560 1038-1041. (doi:10.1210/jcem-60-5-1038)

23 Dimitriadis G, Mitrou P, Lambadiari V, Boutati E, Maratou E, Koukkou E, Panagiotakos D, Tountas N, Economopoulos T \& Raptis SA. Insulin-stimulated rates of glucose uptake in muscle in hyperthyroidism: the importance of blood flow. Journal of Clinical Endocrinology and Metabolism 200893 2413-2415. (doi:10. 1210/jc.2007-2832)

24 Dimitriadis G, Mitrou P, Lambadiari V, Boutati E, Maratou E, Koukkou E, Tzanela M, Thalassinos N \& Raptis SA. Glucose and lipid fluxes in the adipose tissue after meal ingestion in hyperthyroidism. Journal of Clinical Endocrinology and Metabolism 200691 1112-1118. (doi:10.1210/jc.2005-0960)

25 Jorns A, Tiedge M \& Lenzen S. Thyroxine induces pancreatic $\beta$ cell apoptosis in rats. Diabetologia 200245 851-855. (doi:10.1007/ s00125-002-0842-5)

26 Fernandez-Mejia C \& Davidson MB. Regulation of glucokinase and proinsulin gene expression and insulin secretion in RIN-m5F cells by dexamethasone, retinoic acid, and thyroid hormone. Endocrinology 1992130 1660-1668. (doi:10.1210/en.130.3. 1660)

27 Tabak AG, Jokela M, Akbaraly TN, Brunner EJ, Kivimaki M \& Witte DR. Trajectories of glycaemia, insulin sensitivity, and insulin secretion before diagnosis of type 2 diabetes: an analysis from the Whitehall II study. Lancet 2009373 2215-2221. (doi:10.1016/ S0140-6736(09)60619-X)

28 Renauld A, Sverdlik RC \& Andrade LL. Effects of hypothyroidism on serum immunoreactive insulin, free fatty acids and blood sugar in the dog as tested for oral glucose tolerance. Corrective effects of thyroxine therapy. Hormone and Metabolic Research 1974 6 137-141. (doi:10.1055/s-0028-1093878)

29 Ahren B, Lundquist I, Hedner P, Valdemarsson S \& Schersten B. Glucose tolerance and insulin and C-peptide responses after various insulin secretory stimuli in hyper- and hypothyroid subjects before and after treatment. Diabetes Research 19852 95-103.

30 Katsilambros N, Ziegler R, Schatz H, Hinz M, Naier V \& Pfeiffer EF. Intravenous glucose tolerance and insulin secretion in the rat after thyroidectomy. Hormone and Metabolic Research 1972 4 377-379. (doi:10.1055/s-0028-1094037)

31 Harris PE, Walker M, Clark F, Home PD \& Alberti KG. Forearm muscle metabolism in primary hypothyroidism. European Journal of Clinical Investigation 199323 585-588. (doi:10.1111/ j.1365-2362.1993.tb00970.x)

32 Maratou E, Hadjidakis DJ, Kollias A, Tsegka K, Peppa M, Alevizaki M, Mitrou P, Lambadiari V, Boutati E, Nikzas D, Tountas N, Economopoulos T, Raptis SA \& Dimitriadis G. Studies of insulin resistance in patients with clinical and subclinical hypothyroidism. European Journal of Endocrinology 2009160 785-790. (doi:10.1530/EJE-08-0797)

33 Rochon C, Tauveron I, Dejax C, Benoit P, Capitan P, Fabricio A, Berry C, Champredon C, Thieblot P \& Grizard J. Response of glucose disposal to hyperinsulinaemia in human hypothyroidism and hyperthyroidism. Clinical Science 2003 104 7-15. (doi:10. 1042/CS20020154)

34 Dimitriadis G, Mitrou P, Lambadiari V, Boutati E, Maratou E, Panagiotakos DB, Koukkou E, Tzanela M, Thalassinos N \& 
Raptis SA. Insulin action in adipose tissue and muscle in hypothyroidism. Journal of Clinical Endocrinology and Metabolism 200691 4930-4937. (doi:10.1210/jc.2006-0478)

35 Tuzcu A, Bahceci M, Gokalp D, Tuzun Y \& Gunes K. Subclinical hypothyroidism may be associated with elevated high-sensitive C-reactive protein (low grade inflammation) and fasting hyperinsulinemia. Endocrine Journal 200552 89-94. (doi:10.1507/ endocrj.52.89)

36 Dessein PH, Joffe BI \& Stanwix AE. Subclinical hypothyroidism is associated with insulin resistance in rheumatoid arthritis. Thyroid 200414 443-446. (doi:10.1089/105072504323150750)

37 Jackson IM, Prentice CR \& McKiddie MT. The effect of hypothyroidism on glucose tolerance and insulin metabolism. Journal of Endocrinology 197047 257-258. (doi:10.1677/joe.0. 0470257)

38 Fernandez-Real JM, Lopez-Bermejo A, Castro A, Casamitjana R \& Ricart W. Thyroid function is intrinsically linked to insulin sensitivity and endothelium-dependent vasodilation in healthy euthyroid subjects. Journal of Clinical Endocrinology and Metabolism 200691 3337-3343. (doi:10.1210/jc.2006-0841)

39 Roos A, Bakker SJ, Links TP, Gans RO \& Wolffenbuttel BH. Thyroid function is associated with components of the metabolic syndrome in euthyroid subjects. Journal of Clinical Endocrinology and Metabolism 2007 92 491-496. (doi:10.1210/jc.2006-1718)
40 Iacobellis G, Ribaudo MC, Zappaterreno A, Iannucci CV \& Leonetti F. Relationship of thyroid function with body mass index, leptin, insulin sensitivity and adiponectin in euthyroid obese women. Clinical Endocrinology 200562 487-491. (doi:10. 1111/j.1365-2265.2005.02247.x)

41 Bakker SJ, ter Maaten JC, Popp-Snijders C, Slaets JP, Heine RJ \& Gans RO. The relationship between thyrotropin and low density lipoprotein cholesterol is modified by insulin sensitivity in healthy euthyroid subjects. Journal of Clinical Endocrinology and Metabolism 200186 1206-1211. (doi:10.1210/jc.86.3.1206)

42 Chubb SA, Davis WA \& Davis TM. Interactions among thyroid function, insulin sensitivity, and serum lipid concentrations: the Fremantle diabetes study. Journal of Clinical Endocrinology and Metabolism 200590 5317-5320. (doi:10.1210/jc.2005-0298)

43 Utzschneider KM, Prigeon RL, Tong J, Gerchman F, Carr DB, Zraika S, Udayasankar J, Montgomery B, Mari A \& Kahn SE. Within-subject variability of measures of $\beta$ cell function derived from a 2 h OGTT: implications for research studies. Diabetologia 200750 2516-2525. (doi:10.1007/s00125-007-0819-5)

Received 13 August 2010

Accepted 26 August 2010 